\title{
EL MINISTERIO FISCAL ESPAÑOL Y SU RELACIÓN CON EL PODER LEGISLATIVO
}

\author{
Juan Manuel Fernández Aparicio*
}

\begin{abstract}
RESUMEN
La ubicación del Ministerio Fiscal español en la arquitectura constitucional diseñada en 1978 determina una especial relación del fiscal con cada uno de los tres poderes del Estado. Tradicionalmente se ha estudiado por la doctrina la relación con el poder ejecutivo y el judicial mas no podemos olvidar que también mantiene una especial relación con el poder legislativo, siendo éste el aspecto a explorar. El fiscal como defensor nato de la legalidad no puede sustraerse a un cierto control parlamentario sin que ello ponga en peligro su reconocida autonomía constitucional, existiendo un deber de rendición de cuentas al parlamento y un deber de colaboración. Esta colaboración se aprecia en las comisiones de investigación en donde el fiscal culminará el resultado de investigación parlamentaria y ofrece una colaboración indirecta a través del Defensor del Pueblo.
\end{abstract}

\section{FISCAL - CONTROL - PARLAMENTO}

\section{The Spanish prosecution office and its relationship with the legislative}

\begin{abstract}
The position held by the Spanish prosecution office within the constitutional structure designed in 1978 determines a special relationship between the attorney general and each one of the three powers of the state. Traditionally, the subject has been studied by scholars in relation to the executive and the judiciary, but the special relationship with the legislative power cannot be overlooked; this relationship is the subject of the present analysis. The attorney general, as an "ex officio" defender of legality, cannot be free from a certain form of parliamentary control, but that does not endanger bis constitutionally recognized autonomy; there is an accountability duty for the parliament as well as a duty of collaboration. Collaborations can be seen in investigation committees, where the attorney general brings to a close the parliamentary investigation and offers indirect collaboration through the ombudsman.
\end{abstract}

\section{ATTORNEY GENERAL - PROSECUTION OFFICE - PARLIAMENT}

* Doctor en Derecho, Profesor tutor de Derecho Procesal de la Universidad Nacional de Educación a Distancia, Fiscal de la Audiencia Provincial de Jaén, Palacio de Justicia, c/ Arquitecto Berges N ${ }^{\circ}$ 17. 23071. Jaén, España, correo electrónico: libertasveritas@yahoo.es Artículo recibido el 6 de septiembre de 2006 y aceptado para su publicación por el Comité Editorial el 4 de mayo de 2007. 


\section{Consideraciones previas}

$\mathrm{E}$

1 Ministerio Fiscal (en adelante MF) es una de las pocas instituciones del Estado que mantiene relaciones con cada uno de los poderes del mismo. Evidentemente el nivel de relación no es igual con cada uno de ellos porque precisamente la mayor o menor vinculación del MF con un órgano concreto determina la existencia de un modelo judicialista, gubernativo o parlamentario del Ministerio Público. En el caso español se ha querido construir un MF colocado geográficamente en el seno del Poder Judicial pero no formando parte del mismo, manteniendo mecanismos de vinculación con los otros dos poderes del Estado, especialmente con el Poder Ejecutivo.

Es con el Parlamento con el poder que menos relación de sometimiento y control guarda el Ministerio Público. Y ello paradójicamente, por cuanto es a esta institución a la que le corresponde guardar y hacer guardar el principio de legalidad que emana directamente de este poder. Es significativa la ausencia de intervención parlamentaria en todo lo concerniente al nombramiento del Fiscal General del Estado.

Por tanto, la relación del Poder Legislativo con el MF se ve articulada básicamente a través del deber de información al Parlamento de quien es el máximo responsable de la institución y por otra parte y de modo indirecto el MF se relaciona con el Parlamento a través del Defensor del Pueblo, Alto Comisionado de las Cortes Generales.

Como veremos, la reforma al Estatuto Orgánico del Ministerio Fiscal (en adelante EOMF) efectuada por ley 16/2003 de 26 de mayo prácticamente nada ha modificado el escaso papel que al primer poder del Estado se le asigna respecto al control y funcionamiento del Ministerio Fiscal.

\section{El Fiscal General del Estado y su deber de informar a las Cortes Generales. Las Comisiones de investigación Y EL MiNisterio FisCAL}

El Parlamento actúa en el ámbito judicial, proporcionándole al juez su instrumento de trabajo: la ley que tiene que interpretar y que le ha de servir para cumplir la función jurisdiccional de juzgar y hacer ejecutar lo juzgado. El Parlamento interviene igualmente en la elección y selección de los miembros del Consejo General del Poder Judicial.

La relación entre MF y Parlamento hemos de situarla en el marco del capítulo IV del Título I del EOMF que precisamente se rubrica De las relaciones del Ministerio Fiscal con los poderes públicos. De los cuatro preceptos que componen el capítulo sólo dos abordan esta cuestión.

El primero es el art. 9 que determina la obligación del Ministerio Fiscal a través del Fiscal General del Estado de informar al Parlamento mediante una Memoria anual sobre su actividad. Nótese como aclara el precepto que el original se le entregará al gobierno -Poder Ejecutivo- y una copia a las Cortes Generales -Poder Legislativo- y otra al Consejo General del Poder Judicial -Poder Judicial-. Históricamente la obligación de entregar 
una Memoria exclusivamente al gobierno arranca del artículo $15^{1}$ de la Ley Adicional a la Ley Orgánica del Poder Judicial de 14 de octubre de 1882. Como fácilmente se ve, aunque se ha dado un paso en la desvinculación con el Poder Ejecutivo, ésta no es total pues si a éste se le entrega el original, a los otros unas meras copias.

La reforma de mayo de 2003 ha retocado el precepto al añadir que "en todo caso, la citada memoria será presentada por el Fiscal General del Estado a las Cortes Generales en el periodo ordinario de sesiones más próximo a su presentación pública”.

Respecto al segundo de los preceptos, es en el art. 10, el cual no ha sufrido modificación alguna, donde se contempla un derecho de comunicación entre ambas instituciones, con aspiraciones a fijar un cierto control del Parlamento hacia la actividad del Ministerio Público. El artículo 10 EOMF afirma textualmente:

“el MF colaborará con las Cortes Generales a requerimiento de éstas y siempre que no exista obstáculo legal, sin perjuicio de comparecer ante las mismas para informar de aquellos asuntos para los que especialmente fuera requerido. Las Cortes Generales se comunicarán con el MF a través de los Presidentes de las Cámaras”.

Consecuentemente se establece una relación de colaboración pero no se aprecia subordinación en el sentido material. Sí existe subordinación en un sentido formal, como la tiene cualquier órgano del Estado hacia unas Cámaras que actúan como depositarias de la soberanía popular.

Este deber de colaboración aparece también en los artículos 4 y 5 EOMF, por cuanto existe un deber de informar al Parlamento de todo aquello que resulte de su interés. Consecuentemente tanto el Fiscal General del Estado como cualquier miembro de esta institución puede comparecer ante el Parlamento con la única finalidad de informar a los diferentes grupos parlamentarios. Evidentemente se observa un vacío legislativo, en cuanto que no existe un procedimiento específico que determine cómo puede comparecer un miembro del MF ante las Cortes Generales. Históricamente se planteó la cuestión con ocasión de la comparecencia del entonces Fiscal General del Estado y el Fiscal Especial para la lucha contra la droga el día 21 de mayo de 1985. El Presidente de la Comisión

${ }^{1}$ Decía el artículo 15 de la Ley Adicional a la Ley Orgánica del Poder Judicial:

"A fin de mantener la unidad y dependencia del Ministerio Fiscal, los Fiscales de las Audiencias Territoriales tendrán facultades de inspección sobre todos y cada uno de los Fiscales de las Audiencias de lo Criminal del respectivo territorio, a cuyo efecto éstos remitirán a aquéllos, dentro de la primera quincena del mes de mayo, de cada año, una Memoria relativa a la Administración de Justicia en lo criminal en la Audiencia de su circunscripción; y en vista de su resultado los Fiscales de las Audiencias Territoriales les harán las observaciones que estimen oportunas, dando cuenta al Fiscal del Tribunal Supremo, con remisión de otra Memoria durante la primera quincena del mes de julio.

El Fiscal del Tribunal Supremo, a su vez, tomará los acuerdos que conceptúe procedentes; y en exposición razonada dirigida al Gobierno de S.M, manifestará al comenzar cada año judicial el estado de la Administración de Justicia en España, las instrucciones más importantes que haya dado a sus subordinados y las reformas que en su concepto conviniese hacer para el mejor servicio.

Esta Memoria se publicará a la vez que el discurso de apertura de Tribunales a que se refiere el artículo 628 de la Ley sobre Organización del Poder Judicial”. 
decidió aplicar el procedimiento previsto en el artículo 203 del Reglamento del Congreso de los Diputados, que regula las comparecencias de los miembros del gobierno, si bien le introdujo una serie de correctivos y ello atendiendo a la naturaleza del MF, por cuanto no es miembro del gobierno. Concretamente se les prohibió a los diferentes grupos parlamentarios realizar actos de censura al fiscal, y se eliminó la posibilidad de votar una vez finalizada la comparecencia del miembro del Ministerio Público.

El artículo 10 EOMF sienta las bases de una posible relación fructífera entre las Cortes Generales y el MF. De este precepto se desprende claramente que el Ministerio Público no es un instrumento del Parlamento, pero que éste puede dirigirse directamente a él sin pasar por ningún mecanismo de control o de tamiz como podía ser el Poder Ejecutivo. Este aspecto es importante pues a diferencia de lo que ocurre en las relaciones entre MF y gobiernos autonómicos, en donde se precisa claramente en el artículo 11 del Estatuto Orgánico del MF que esa comunicación se realizará a través del Ministerio de Justicia, el artículo 10 del Estatuto aclara que se realizará directamente la comunicación con la única salvedad de respetar lo que diga la propia ley "sin otros obstáculos que los que la ley imponga”.

Por consiguiente, no es este artículo 10 un precepto innecesario, sino todo lo contrario. Ello es así, por cuanto recuerda nuevamente que el fiscal es una institución que ha de servir a todos los poderes del Estado. Por tanto no es, como lo ha sido históricamente, sólo un órgano gubernamental.

Además, el propio Parlamento ha recordado que con base al ya citado artículo 10 EOMF puede ampliarse, sin más límites que los que el propio Parlamento quiera fijar y el ya fijado por la Carta Magna, la intervención de las Cámaras en todo aquello que afecte a la actuación del MF.

Esta función de colaboración también se comprueba en el art. 76 CE. La Constitución, en la línea de los textos constitucionales occidentales, incorpora en su articulado la regulación expresa de las comisiones de investigación fijando de esta manera, al más alto nivel, un instrumento específico de fiscalización del Ejecutivo en manos de las Cortes. El fiscal aparece como colaborador en esta misión al afirmar el art. 76.1 in fine "sus conclusiones no serán vinculantes para los tribunales, ni afectarán a resoluciones judiciales, sin perjuicio de que el resultado de la investigación sea comunicado al MF para el ejercicio, cuando proceda, de las acciones oportunas”. Tanto el artículo 52 del Reglamento ${ }^{2}$ del Congreso de los Diputados como el artículo 60 del Reglamento ${ }^{3}$ del Senado establecen la posibilidad de que una vez finalizada la comisión de investigación, ésta le comunique al MF el resultado de la investigación, y ello con la evidente finalidad de exigencia de responsabilidades penales por parte del Ministerio Público. Esto no significa que la

\footnotetext{
${ }^{2}$ Concretamente el art. 52.5 indica:

"Las conclusiones aprobadas por el Pleno de la Cámara serán publicadas en el Boletín Oficial de las Cortes Generales y comunicadas al gobierno, sin perjuicio de que la Mesa del Congreso dé traslado de las mismas al Ministerio Fiscal para el ejercicio, cuando proceda, de las acciones oportunas".

${ }^{3}$ El apartado $5^{\circ}$ del art. 60 afirma: "El resultado de las investigaciones será comunicado, en su caso, al Ministerio Fiscal para el ejercicio, cuando proceda, de las acciones que correspondan”.
} 
comisión de investigación le ordene al MF que actúe de una forma concreta, quedando vedada la posibilidad de darle instrucciones sobre el sentido de sus intervenciones. Esta realidad no significa menoscabo alguno de la relación entre el Parlamento y el MF sino la constatación de un hecho: el deber de respeto a la autonomía que la Carta Magna le reconoce al Ministerio Público. En definitiva, las Cortes están excitando la intervención del fiscal, en un nivel similar al reconocido al gobierno en el artículo 8.1 EOMF, debiendo recordar una vez más que el Poder Ejecutivo no ejerce un poder jerárquico sobre el MF, no existiendo obediencia de esta institución frente al gobierno.

Similar previsión encontramos en la mayoría de los Estatutos de Autonomía. ${ }^{4}$ De este modo se confía en el fiscal como puente entre los distintos poderes del Estado. Esta conexión a través del MF entre los diferentes poderes del Estado no debe ser obstáculo alguno para que el fiscal cumpla cada una de sus misiones constitucionales, incluida la de velar por la independencia judicial. Coincidimos con Navas Castillo ${ }^{5}$ cuando afirma:

“el art. 76.1 c, lejos de atentar contra la independencia judicial sancionada en el art. 117 de nuestra Carta Magna, no hace más que garantizar la misma, al atribuir al MF -integrado con autonomía funcional en el Poder Judicial- la facultad de interponer libremente las acciones penales pertinentes".

Es pues la autonomía la que garantiza que el fiscal pueda continuar investigando lo que las Cortes comenzaron, autonomía no sólo frente al Poder Judicial como afirma la autora citada, sino sobre todo frente al Poder Ejecutivo.

En definitiva, las Cortes Generales están invitando al MF a que cumpla con la legalidad. ${ }^{6}$ La Constitución no hubiera entregado el resultado de una investigación al fiscal si al mismo tiempo no hubiese diseñado un modelo de Ministerio Público con cierto grado de autonomía. Por eso no extraña que en Alemania ${ }^{7}$ donde el fiscal carece de esa autonomía no se le entregue el resultado de la investigación parlamentaria.

\footnotetext{
${ }^{4}$ Las conclusiones de las comisiones de investigación serán entregadas al Ministerio Fiscal para que éste ejerza las acciones cuando considere oportuno en los Reglamentos de los Parlamentos Autonómicos siguientes: Andalucía (art. 53.5), Aragón (art. 64.2), Asturias (art. 74.6), Baleares (art. 51.5), Canarias (art. 49.5), Cantabria (art. 50.5), Castilla-León (art. 50.7), Extremadura (art. 50.5), Galicia (art. 52.5), Navarra (art. 61.6) y Valencia (art. 74.6).

${ }^{5}$ Navas Castillo, F., "Las Comisiones de Investigación y el Poder Judicial", en Revista del Poder Judicial, número 60, cuarto trimestre 2000, Madrid, p. 17.

${ }^{6}$ La legalidad ordinaria (art. 3.4 EOMF y el art. 105 LECr) obliga al Ministerio Público a ejercitar la acción penal si de delito público se tratase.

${ }^{7}$ Art. 44.4 de la Ley Fundamental de Bonn: "Las resoluciones de la comisión de investigación no podrán ser sometidas a la consideración judicial. Los Tribunales quedan en libertad para apreciar y calificar los hechos que son objeto de investigación”.
} 


\section{El Ministerio Fiscal y su relación con el Defensor del Pueblo como Alto Comisionado del Parlamento}

Con diversas denominaciones (Comisionado Parlamentario, Promotor de la Justicia, Médiateur, Defensor del Pueblo, etc.), la figura del Ombudsman se ha introducido en las diferentes constituciones especialmente desde la Segunda Guerra Mundial. La razón de ser de su nacimiento obedece a la necesidad de crear mecanismos de control para vigilar la actividad de la Administración.

El Defensor del Pueblo español encuentra su posición constitucional en el artículo 54 de nuestra Carta Magna que lo define como un Alto Comisionado de las Cortes Generales para la defensa de los derechos y libertades, a cuyo efecto le otorga la facultad de supervisar la actividad de la Administración dando cuenta a las Cortes Generales.

La Ley Orgánica 3/1981, de 6 de abril, del Defensor del Pueblo, nace en cumplimiento del mandato constitucional del artículo 54 fijando el estatuto por el que se va a regir esta institución. Completa el marco normativo el Reglamento de organización y funcionamiento del Defensor del Pueblo, aprobado por las Mesas del Congreso y del Senado, a propuesta del Defensor de Pueblo, en su reunión conjunta de 6 de abril de $1983 .{ }^{8}$

La finalidad específica y característica del Defensor del Pueblo es la de ejercer un control de la constitucionalidad y legalidad ordinaria de la actuación de la Administración, a través de un procedimiento basado en reglas sumamente simples (investigación sumaria e informal). Para alcanzar tal fin cuenta con los instrumentos imprescindibles y entre ellos se encuentra la colaboración con el MF en la consecución del fin común de defender la legalidad y el interés social. Por ello el Defensor del Pueblo puede supervisar la actividad de todas las Administraciones Públicas, de cualquier naturaleza, incluidas la militar y judicial, por lo que se le reconoce en definitiva lo que la doctrina ha denominado "competencia universal", debiéndosele añadir la acción de responsabilidad que establece el artículo 26 de su ley orgánica.?

Las relaciones con el MF se articulan básicamente a través de tres preceptos: ${ }^{10} \mathrm{el}$ artículo 13 , el artículo 24 y el artículo 25. Concretamente, el artículo 24 recoge en su

${ }^{8}$ BOE número 92, de 18 de abril de 1983; corrección de errores en BOE número 97, de 23 de abril. Modificado por Resolución de las Mesas del Congreso de los Diputados y del Senado de 21 de abril de 1992.

${ }^{9}$ Dice el artículo 26 de la Ley Orgánica del Defensor del Pueblo:

"El Defensor del Pueblo podrá, de oficio, ejercitar la acción de responsabilidad contra todas las autoridades, funcionarios y agentes civiles del orden gubernativo o administrativo, incluso local, sin que sea necesaria en ningún caso la previa reclamación por escrito".

${ }^{10}$ Dicen estos tres preceptos de la Ley Orgánica del Defensor del Pueblo:

Artículo 13: "Cuando el Defensor del Pueblo reciba quejas referidas al funcionamiento de la Administración de Justicia, deberá dirigirlas al Ministerio Fiscal para que éste investigue su realidad y adopte las medidas oportunas con arreglo a la ley, o bien dé traslado de las mismas al Consejo General del Poder Judicial, según el tipo de reclamación de que se trate; todo ello sin perjuicio de la referencia que en su informe general a las Cortes Generales pueda hacer al tema".

Artículo 24: “1. La persistencia en una actitud hostil o entorpecedora de la labor de investigación del Defensor del Pueblo por parte de cualquier Organismo, funcionarios, directivo o persona al servicio 
apartado segundo la posibilidad de acudir al MF para que éste ejercite la acción penal si la autoridad o funcionario público desobedeciera al Defensor del Pueblo.

El artículo 13 recoge la necesaria intervención del MF en la tramitación de las quejas cuando éstas afecten al funcionamiento de la Administración de Justicia. Consecuentemente, es al fiscal a quien se le encomienda la investigación de la queja del ciudadano y una vez que éste ha investigado, da cuenta al Defensor del Pueblo del resultado. El Defensor del Pueblo, si considerara que es un asunto de competencia del Consejo General del Poder Judicial, se dirigirá al órgano de gobierno de los jueces. Clara y significativa es la Instrucción 5/1987 de 30 de octubre de la FGE ${ }^{11}$ que recuerda el papel eminentemente activo del fiscal que no sólo debe informar, sino también "remover cuantos obstáculos existiesen en el procedimiento al que se refiere la queja”.

La intervención del MF no estaba prevista en la proposición de ley que se discutió en el Congreso de los Diputados. El artículo 15, ${ }^{12}$ actual artículo 13, permitía la comunicación directa del Defensor del Pueblo con el mismo CGPJ cuando se produjera

de la Administración pública podrá ser objeto de un informe especial, además de destacarlo en la sección correspondiente de su informe anual.

2. El funcionario que obstaculizare la investigación del Defensor del Pueblo mediante la negativa o negligencia en el envío de los informes que éste solicite, o en facilitar su acceso a expedientes o documentación administrativa necesaria para la investigación, incurrirá en el delito de desobediencia. El Defensor del Pueblo dará traslado de los antecedentes precisos al Ministerio Fiscal para el ejercicio de las acciones oportunas".

Artículo 25: "1. Cuando el Defensor del Pueblo, en razón del ejercicio de las funciones propias de su cargo, tenga conocimiento de una conducta o hechos presumiblemente delictivos lo pondrá de inmediato en conocimiento del Fiscal General del Estado.

2. En cualquier caso, el Fiscal General del Estado informará periódicamente al Defensor del Pueblo, o cuando éste lo solicite, del trámite en que se hallen las actuaciones iniciadas a su instancia.

3. El Fiscal General del Estado pondrá en conocimiento del Defensor del Pueblo todas aquellas posibles irregularidades administrativas de que tenga conocimiento el Ministerio Fiscal en el ejercicio de sus funciones".

${ }^{11}$ Memoria elevada al Gobierno de S.M. por el Fiscal General del Estado, Excmo. Sr. D. Javier Moscoso del Prado y Muñoz, Madrid, 1988, página 481. Esta Instrucción está dirigida al Fiscal Jefe de Alicante.

"El art. 13 de la citada Ley Orgánica obliga al Ministerio Fiscal a que actúe a los fines de remover cuantos obstáculos existiesen en el procedimiento al que se refiera la queja, y a procurar la pronta terminación del mismo. Es obligado en este tipo de reclamaciones prestar la máxima atención e informar a mi Autoridad pormenorizadamente de las incidencias procesales o de otro tipo que puedan existir o haber existido; la indicación de la posición y actitud del Ministerio Fiscal y las medidas adoptadas en su caso, para corregir las deficiencias observadas en orden a la queja formulada. En todo caso, V.I. deberá seguir informándome periódicamente hasta la terminación del procedimiento al que se refiere la queja...”.

12 "El Defensor del Pueblo velará por el cumplimiento efectivo del mandato contenido en el artículo 24 de la Constitución en el ámbito de la Administración de Justicia, para lo cual podrá reclamar de las instituciones y organismos competentes la información que considere oportuna a estos efectos, sin que en ningún caso su acción pueda interferir en el ejercicio de la potestad jurisdiccional.

Cuando como resultado de su investigación considere que se ha producido un funcionamiento anormal de la Administración de Justicia, lo pondrá en conocimiento del Consejo General del Poder Judicial, a los efectos oportunos.

Anualmente informará a las Cortes Generales del estado de sus gestiones en el ámbito de la Administración de Justicia y en cualquier momento y de forma extraordinaria si las circunstancias así lo aconsejaran”.

Boletín Oficial de las Cortes Generales, Congreso de los Diputados, serie B, número 39-I, de 20 de junio de 1979. 
un funcionamiento anormal de la Administración de Justicia. La enmienda número 31 presentada por UCD justificó la necesidad de intervención del MF como mecanismo que garantizase a su vez el principio de división de poderes, la independencia de los Tribunales, así como la propia naturaleza del Ministerio Público.

La ley debe abrir la posibilidad de que el Defensor del Pueblo pueda supervisar la actividad del MF. El artículo 13 LODP, que ha previsto dirigir al Ministerio Público las quejas que reciba sobre el funcionamiento de la Administración de Justicia, ha olvidado determinar quién investigará las quejas que se refieran a errores o disfunciones en la actuación del MF. Evidentemente, el papel fundamental que juega el Ministerio Público en el desempeño del servicio público de la Administración de Justicia determina la importancia que alcanza la supervisión de su funcionamiento en el desarrollo de las funciones que le están encomendadas. Ante el silencio de la ley debemos entender que el Defensor del Pueblo puede y debe directamente investigar las disfunciones del MF de las que tenga conocimiento, con total respeto, evidentemente, respecto de las competencias que le son propias. Una vez finalizada su investigación, deberá notificárselo al Fiscal General del Estado para que éste adopte las medidas que tenga por convenientes, asistido en todo momento por el Consejo Fiscal y la Inspección Fiscal.

Por último, la intervención del MF se observa igualmente en el artículo 25 LODP en donde se prevé una colaboración recíproca entre ambas instituciones, ya que el Defensor del Pueblo pondrá en conocimiento del Fiscal General del Estado aquellos hechos susceptibles de ser delictivos de que conozca por razón de su cargo e, igualmente, el Fiscal General del Estado pondrá en conocimiento del Defensor del Pueblo todas aquellas posibles irregularidades administrativas que conozca el MF con ocasión del ejercicio de sus funciones. El texto originario ${ }^{13}$ aumentaba la colaboración, por cuanto preveía la obligación del Fiscal General del Estado de informar al Defensor del Pueblo del resultado de las investigaciones realizadas por la Fiscalía.

La posibilidad de incorporar la institución del Ombudsman a los Estatutos de autonomía pese al silencio constitucional obliga aun de forma somera referirnos a esta realidad en cuanto el MF se ha encontrado con la obligación de colaborar con estas instituciones que van a desarrollar una función similar, cuando no idéntica que su homónimo constitucional, pero limitándose al ámbito que le es propio. ${ }^{14}$

${ }^{13}$ El artículo 27 de la proposición de ley presentada al Congreso de los Diputados tenía la siguiente redacción:

“1. Cuando el Defensor del Pueblo, en razón del ejercicio de las funciones propias de su cargo, tenga conocimiento de una conducta o hechos presumiblemente delictivos, lo pondrá de inmediato en conocimiento del Fiscal General del Estado.

2. En cualquier caso el Fiscal General del Estado vendrá obligado a informar periódicamente al Defensor del Pueblo, o cuando éste lo solicite, de la marcha de las actuaciones iniciadas a instancia suya y del resultado de las mismas.

3. El Fiscal General del Estado pondrá en conocimiento del Defensor del Pueblo todas aquellas posibles irregularidades administrativas de que tenga conocimiento el Ministerio Fiscal en el ejercicio de sus funciones".

${ }^{14}$ Un estudio completo sobre los defensores del pueblo de las comunidades autónomas puede consultarse la monografía de Díez Bueso, Laura (1999). 
Consecuentemente el fiscal se convierte en un valedor de la institución que actúa por mandato de las Cámaras, gracias a lo cual se han detectado un gran número de disfunciones que el Defensor del Pueblo ha trasladado a los depositarios de la soberanía popular y que han provocado en algunas ocasiones la reforma de la legislación vigente acogiendo la recomendación del Defensor del Pueblo. ${ }^{15}$

\section{LA CRITICABLE AUSENCIA DE INTERVENCIÓN PARLAMENTARIA EN La designación del Fiscal General del Estado}

Prescindiendo de antecedentes más remotos, el grupo parlamentario de Izquierda Unida presentó en fecha 18 de marzo de 1997, a través de las diputadas Almeida Castro y Aguilar Rivero, ${ }^{16}$ una moción instando al gobierno a admitir la participación del Parlamento en el nombramiento ${ }^{17}$ del Fiscal General del Estado ya que el actual art.124.4 de nuestra Carta Magna residencia básicamente en el Gobierno la facultad de nombrar a

${ }^{15}$ Entresacamos las más destacables dirigidas al Poder Judicial: la 8/1983, sobre dilaciones en los procedimientos judiciales; la 9/1983, sobre la ejecución de las sentencias de la Jurisdicción contencioso administrativa; la 12/1983, sobre la situación de los llamados "locos judiciales"; la 7/1984, dirigida al Fiscal General del Estado sobre adopción de medidas para el cumplimiento de las decisiones judiciales por parte de la Administración; la 8/1984, dirigida al Ministerio de Justicia, sobre la situación de los jueces, fiscales y secretarios sustitutos y en régimen de provisión temporal; la 3/1985, de 13 de febrero, dirigida al Presidente del Consejo General del Poder Judicial y al Fiscal General del Estado sobre interpretación del artículo 211 del Código Civil; la 11/1986, de 24 de marzo, dirigida al Fiscal General del Estado sobre retrasos en la Jurisdicción Penal y emisión a los centros penitenciarios, mediante telegrama del contenido esencial del fallo de las sentencias; la 47/1986, de 10 de diciembre, dirigida al Ministro de Justicia sobre aplicación de los artículos 8.1 y 9.1 del Código Penal (enfermos mentales); la 51/1986, dirigida a las Cortes Generales sobre prescripción de faltas cometidas por jueces y magistrados; la 46/1987, de 19 de noviembre, dirigida al Presidente del CGPJ, al Ministro de Justicia y al FGE, en relación con la situación penitenciaria; la 24/1990, formulada con ocasión del informe a las Cortes Generales correspondiente a 1990, sobre modificación de la legislación penal y procesal del menor; la 46/1995, de 26 de julio, sobre actuación profesional de los letrados cuando éstos son designados de oficio (Boletín Oficial de las Cortes Generales, Cortes Generales, VI Legislatura, serie A, número 7, página 53); la 21/1995, de 3 de mayo, sobre deficiencias en materia de seguridad e higiene en diversos edificios de la Administración de Justicia de Sevilla (Boletín Oficial de las Cortes Generales, Cortes Generales, VI Legislatura, Serie A, número 7, página 42); la 4/1996 sobre adopción de medidas en la Sala $1^{a}$ del Tribunal Supremo y modificación del recurso de casación con objeto de normalizar el atraso generalizado que presenta dicha Sala; la 25/1996 sobre intervención del juzgado de guardia en la puesta en libertad de extranjeros internados (Informe anual 1996).

${ }^{16}$ Boletín Oficial de las Cortes Generales, Congreso de los Diputados, año 1997, Sexta Legislatura, número 119, de 25 de marzo de 1997, páginas 9 y 10.

17 "El Congreso de los Diputados insta al gobierno para que inicie y presente a las Cortes Generales una modificación del Estatuto Orgánico del Ministerio Fiscal, que contemple, al menos, los siguientes aspectos:

1. Participación de las Cortes Generales en la elección del Fiscal General del Estado, mediante la comparecencia del candidato o candidatos propuestos por el gobierno ante las Comisiones de Justicia de ambas Cámaras.

2. Limitación del período de mandato del Fiscal General, y de determinados destinos de la carrera fiscal servidos por fiscales de la categoría primera, a cinco años, al término de los cuales no pueden ser reelegidos y 
éste habiendo escuchado al Consejo General del Poder Judicial. Igualmente pretendían que se reformase el EOMF para que limitase a cinco años la duración del mandato del Fiscal General del Estado. También pedían que la limitación de este mandato se extendiera a determinados destinos de la carrera fiscal, concretamente a los servidos por los fiscales de la categoría primera. Este grupo puntualizaba que una vez transcurridos estos cinco años no podían resultar reelegidos. Durante la duración del mandato no podían ser cesados salvo por causas objetivas y legalmente establecidas (renuncia, incurrir en causa de incapacidad, pena de inhabilitación, etc.).

En conclusión, las medidas que se proponían eran tendentes a garantizar el principio de imparcialidad de quien preside la institución. La solución legislativa que proponía esta moción no constituye una novedad pues ya en los trabajos parlamentarios de nuestra Carta Magna se planteó la posibilidad de que el FGE fuese nombrado por el Rey a propuesta del Congreso de los Diputados y para un período de cinco años. Sin embargo, la propuesta que se aprobó con fecha de 27 de mayo de 1997 por el Congreso de los Diputados parte del análisis y respeto al texto constitucional. En concreto, la propuesta que se hacía era del siguiente tenor:

"El candidato propuesto por el gobierno para ser nombrado Fiscal General del Estado por el Rey comparecerá, tras ser oído por el Consejo General del Poder Judicial, ante la Comisión de Justicia e Interior del Congreso de los Diputados, para que los grupos parlamentarios puedan tener conocimiento de sus méritos y trayectoria profesional que les permita expresarse sobre su idoneidad para desempeñar el cargo".

Se introduce pues un importante matiz al modelo constitucional de proposición y nombramiento del Fiscal General del Estado ya que, como sabemos, la Carta Magna nada dice de la participación del Poder Legislativo en la designación de esta importante figura constitucional. La Constitución efectivamente calla sobre esta cuestión, lo cual no debe significar que expresamente esté vetando la posibilidad de introducir mecanismos que buscando precisamente el respeto al también principio constitucional de imparcialidad puedan colaborar en el nombramiento del FGE, mecanismos admisibles siempre y cuando no supongan menoscabo alguno al poder del gobierno en lo referente a esta materia.

La propuesta del Pleno del Congreso de los Diputados presenta aspectos positivos que debemos de destacar, sin perjuicio de poner de relieve aspectos que requieren algún tipo de matización.

durante los que no pueden ser cesados salvo por causas objetivas y legalmente establecidas (renuncia, incurrir en causas de incapacidad, pena de inhabilitación, ...).

3. Presentación de la Memoria Anual de la Fiscalía ante las Cortes, compareciendo personalmente el Fiscal General ante las Comisiones de Justicia para su explicación, así como cuando sea requerido para informar sobre asuntos de su competencia, siempre que no exista obstáculo legal para ello.

4. Actuación independiente del Ministerio Fiscal respecto del gobierno, si bien pudiera éste, al igual que las Cortes Generales o el Consejo General del Poder Judicial, solicitar su actuación en defensa de la legalidad, de los derechos de los ciudadanos o del interés público". 
En primer lugar, es sumamente positivo que el Poder Legislativo pueda intervenir en la designación de esta alta personalidad del Estado. El Poder Legislativo, como conocemos, sí tiene mecanismos de comunicación, y en cierto modo de control, sobre la actividad del Fiscal General del Estado. Cuando decimos de control no lo estamos diciendo en un sentido político, sino en el sentido de que la representación del pueblo español tiene el derecho y el deber de conocer si una institución del Estado tan importante como la Fiscalía General actúa dentro del marco constitucional. Así, como hemos tenido ocasión de analizar, el propio artículo $76 \mathrm{CE}$ establece la necesidad de que el FGE pueda recibir por parte del Congreso de los Diputados o del Senado el resultado de las comisiones de investigación parlamentarias. El propio Estatuto recoge en el artículo 9 la obligación que tiene la Fiscalía General de remitir a las Cortes Generales una copia de su Memoria anual, de forma similar a la Memoria que remite el Defensor del Pueblo a las propias Cortes Generales. El artículo 10 EOMF permite a las Cortes Generales exigir la presencia del Fiscal General del Estado para que informe de aquellos asuntos que en concreto le indique la propia Cámara.

Existe pues un marco de interrelación y cooperación entre el Poder Legislativo y la Fiscalía General del Estado. Este marco, además, se ha visto incrementado por la práctica parlamentaria en la que se ha puesto de relieve por un lado la preocupación del Parlamento en la actuación de cada FGE y, por otro, se ha asumido desde la Fiscalía General la necesidad de colaborar más estrechamente con este poder del Estado.

El acuerdo aprobado por el Congreso de los Diputados viene a consagrar la necesidad de intervención de este poder del Estado como mecanismo que pueda al menos atemperar la constatada vinculación ideológica del Fiscal General del Estado con el gobierno que lo nombra, pues, como recuerda García Mexía, ${ }^{18}$ la razón de ser de la intervención de las Cortes en el nombramiento de las principales autoridades del Estado reside básicamente en el deseo de preservar a la institución de que se trate a una excesiva (caso del Tribunal Constitucional, pues una parte de sus miembros son elegidos por el gobierno) o de toda (caso del Consejo General del Poder Judicial, Tribunal Constitucional y Defensor del Pueblo) influencia gubernamental, para de esta manera asegurar al máximo la fiabilidad de sus labores de control. Este mismo fin mueve la intervención de las Cortes en los nombramientos de las llamadas "Administraciones independientes". ${ }^{19}$ Es pues una propuesta encaminada a garantizar el principio de imparcialidad de quien ocupa la cabeza de la institución.

Sin embargo, mucho me temo que la moción de 27 de mayo de 1997 por la que se le instaba al gobierno a presentar un proyecto de ley de reforma del Estatuto Orgánico del Ministerio Fiscal, que entre otras cuestiones contemplara la designación del Fiscal General del Estado, fue fruto de un momento coyuntural y prueba de ello es el tiempo transcurrido desde entonces y el mantenimiento del actual statu quo.

18 García Mexía, P., "El poder en sempiterna crisis: apuntes de la actualidad sobre las Cortes Generales“, en Revista del Poder Judicial, número 60, cuarto trimestre 2000, Madrid, p. 62.

${ }^{19}$ Este es el caso del Consejo de Administración del ente público Radio Televisión Española, Gobernador del Banco de España o vocales de la Junta Electoral Central. 
Un nuevo intento, el Grupo Parlamentario mixto presentó en fecha 3 de mayo de 2000 una proposición de ley para la modificación del sistema de designación del Fiscal General del Estado. ${ }^{20}$ Concretamente fue el diputado Saura Laporta, del Grupo Iniciativa per Catalunya-Verds, al que le correspondió defender la proposición de ley. Se proponía una nueva redacción al artículo 29 del $\mathrm{EOMF}^{21}$ que básicamente venía a recoger lo acordado en fecha 27 de mayo de 1997. Como bien señala este diputado, el gobierno no ha cumplido el mandato parlamentario y en el llamado "Pacto de la Justicia" no se recogió ninguna alusión que pueda permitir afirmar que el gobierno fuera a cumplir con el mandato aprobado por el Congreso, como se comprobó en la reforma del mes de mayo de 2003. La votación en el Pleno del Congreso es ciertamente significativa: de los 289 votos emitidos sólo 14 fueron a favor de la propuesta, en contra 272 votos, y 3 abstenciones. ${ }^{22}$ De las intervenciones de los diferentes grupos se puso de manifiesto que no hay intención alguna en reformar el modo de nombramiento del Fiscal General del Estado. Las razones que se argumentan para rechazar la propuesta son distintas por parte de cada uno de los grupos políticos y que sucintamente vamos a recoger:

1. El Partido Popular, a través de su portavoz Sr. Ollero Tassara, manifestó que no era necesario modificar el sistema de nombramiento porque acarrearía cambiar la Constitución. El modelo que se propone es un modelo parlamentario que no fue acogido en nuestra Carta Magna: admitir la propuesta sería, según este grupo, desapoderar al Poder Ejecutivo de una potestad que le ha atribuido la Constitución. Por otra parte, admitir la intervención del Parlamento determinaría un conflicto de competencias y de enfrentamiento entre los tres poderes del Estado, que en nada ayudaría a la pretendida imparcialidad del Fiscal General del Estado.

${ }^{20}$ Proposición de Ley 122/000025, para la modificación del sistema de designación del Fiscal General del Estado, Boletín Oficial de las Cortes Generales, Congreso de los Diputados, séptima legislatura, 8 de mayo de 2000, número 34-1, páginas 1 y siguientes.

${ }^{21}$ El artículo 29 EOMF que se proponía tenía el siguiente tenor literal:

“1. El Fiscal General del Estado será nombrado por el Rey, a propuesta del gobierno entre juristas de reconocido prestigio, con más de quince años de ejercicio profesional efectivo.

2. Antes de ser propuesto, el candidato comparecerá, tras ser oído el Consejo General del Poder Judicial, ante la Comisión de Justicia e Interior del Congreso de los Diputados, para que, examinados sus méritos y trayectoria profesional, se formulen y aprueben, en su caso, propuestas de resolución sobre su idoneidad para desempeñar el cargo.

3. El Fiscal General del Estado prestará ante el Rey el juramento o promesa que previene la ley y tomará posesión del cargo ante el Pleno del Tribunal Supremo.

4. El Fiscal General del Estado tiene un mandato de cinco años, no renovable, si bien permanecerá en el cargo hasta el nombramiento del que le sustituya. Será también cesado por el Rey, a propuesta del gobierno, oído el Consejo General del Poder Judicial, tras una resolución de la Comisión de Justicia e Interior del Congreso de los Diputados en este sentido, o por los motivos previstos en el artículo 46 del presente Estatuto".

${ }^{22}$ Votaron en contra el Grupo Popular, el Grupo Socialista, Convergencia y Unión y Coalición Canaria. Votaron a favor Izquierda Unida, Grupo Mixto y Partido Nacionalista Vasco. 
2. El Grupo Socialista, en boca del diputado López Aguilar, actual inquilino de la calle San Bernardo (Ministerio de Justicia), no estaba conforme con fijar un período de duración si ello suponía vincular a un gobierno entrante a la continuidad de un Fiscal General del Estado que no ha sido designado por ese gobierno, hasta el punto de condenar a un gobierno a soportar a un FGE que no goza de su confianza. Por otra parte, consideraba que no era necesario introducir en el nombramiento al Poder Legislativo, por cuanto el modelo constitucional no lo había previsto y como tal modelo, debía ser mantenido.

No obstante en la actualidad y a raíz del nombramiento como Fiscal General del Estado del Sr. Conde Pumpido se está barajando la posibilidad de fijar un mandato de 4 años, con causas tasadas de cese.

3. El Grupo de Convergencia y Unión, a través del diputado Silva Sánchez, rechazó la propuesta en cuanto que ésta suponía la introducción de un modelo parlamentario, si bien se mostró favorable, aunque paradójicamente votase en contra, a aceptar fijar un período de duración en el cargo de Fiscal General del Estado, amovible únicamente por motivos objetivos. Aprovechó la ocasión para recordarle al gobierno la necesidad de modificar este aspecto.

Insignes miembros de la propia carrera fiscal han venido defendiendo este retocamiento en lo referente al nombramiento del Fiscal General del Estado. Narváez Rodríguez $^{23}$ defiende esta iniciativa legislativa, por cuanto dota a la figura del FGE de aquellas garantías necesarias para el ejercicio de sus funciones, que lo hagan merecedor del respeto y la confianza de la ciudadanía española, que hoy por hoy se encuentra aún muy lejos de hallar dicho reconocimiento.

Roig Bustos ${ }^{24}$ propone que el Fiscal General del Estado sea nombrado por el Parlamento con una mayoría cualificada, como puede ser 3/5, desplazando la competencia del gobierno a las Cortes Generales. Según este autor, al ser el FGE una institución de control no causaría extrañeza que al igual que otros organismos como el Defensor del Pueblo o el Consejo de RTVE fuese un órgano de designación parlamentaria, de este modo se alcanzaría la legitimidad democrática que otorgaría al FGE una estabilidad hasta ahora desconocida, alcanzando el efecto beneficioso a toda la institución al lograr acabar con la inestabilidad absolutamente incompatible con las misiones asignadas. El fiscal ya no sería una institución a caballo entre los diferentes poderes del Estado. Si al fiscal le corresponde defender la legalidad, el Parlamento es su creador; si el fiscal defiende a la sociedad, el Parlamento representa a la sociedad.

Aunque me muestro favorable a la intervención del primer poder del Estado en la selección de quién debe ser Fiscal General del Estado, no debemos alterar en demasía

${ }^{23}$ Narváez Rodríguez, A., "El Fiscal General del Estado y su relación con el gobierno. Reflexiones sobre su designación, mandato y cese", en Estudios Jurídicos, Ministerio Fiscal, Ministerio de Justicia, volumen V, Madrid, 2000, p. 562.

${ }^{24}$ Roig Bustos, L., "Por un Fiscal del Estado de designación parlamentaria", en Revista Jueces para la Democracia, número 18, Madrid, 1993, pp. 23 y siguientes. 
el texto constitucional so pena de reformarlo por la vía de hecho. El Parlamento debe intervenir pero no entre la intervención del Consejo y la propia gubernamental porque sería inconstitucional. Estaríamos creando un trámite intermedio entre el dictamen del órgano de gobierno del Poder Judicial y el nombramiento por el gobierno, teniendo en cuenta que ello significaría añadir un inciso intermedio al texto constitucional. La Constitución no ha previsto expresamente esta intervención en este momento, lo que no cierra la posibilidad de que lo haga a priori. Por tanto, si realmente queremos respetar el texto constitucional resulta evidente que la CE no nombra al Poder Legislativo, luego incluirlo entre el informe del Consejo General del Poder Judicial y el posterior acuerdo del Consejo de Ministros resultaría contrario al texto constitucional. La CE lo que dice es que la propuesta la hace el gobierno, el cual previamente ha escuchado al CGPJ, pero entre el dictamen del Consejo y el acuerdo gubernamental no se ha previsto en la Carta Magna la intervención de ningún otro órgano o poder del Estado.

Siguiendo con la argumentación, resulta evidente que es positivo que el Parlamento intervenga, pero lo habrá de hacer con anterioridad al dictamen del Consejo General del Poder Judicial.

Evidentemente esta intervención del Poder Legislativo con carácter inicial y previo a la de los otros dos poderes del Estado tendrá el valor de contar con el posicionamiento de las Cámaras. Esta intervención, aunque preceptiva en nuestra opinión, nunca podrá tener con el actual texto constitucional carácter vinculante para el gobierno. En consecuencia, el sistema propuesto no tendrá más valor que el de ser la opinión de los representantes de la soberanía popular. El Ejecutivo podrá aceptar o rechazar el contenido y las conclusiones o bien asumirlas, pero está claro que ante la opinión pública el gobierno intentará lograr el respaldo parlamentario y cuanto más amplio sea éste mejor.

El informe sólo será vinculante para el gobierno en lo referente a la observancia de los requisitos legales previos y no así en los atinentes a la idoneidad o inidoneidad del candidato, y ello porque el gobierno debe respetar la ley constitucional y la ley ordinaria, por lo que no es menoscabo alguno a su competencia que el informe de la Cámara o el propio del Consejo General del Poder Judicial le vincule exclusivamente este aspecto de legalidad.

En conclusión, resulta evidente que con el parecer favorable de todos los poderes del Estado la legitimidad democrática del candidato a ser Fiscal General del Estado se vería reforzada y el propio candidato, aunque deudor de quien lo nombre, deberá ser consciente de que contó también con el visto bueno de los otros dos poderes del Estado, lo cual redundará en la imparcialidad del mismo.

\section{Conclusiones}

Nuestra Carta Magna al igual que su antecesora republicana de 1931 constitucionaliza la importante institución del Ministerio Publico arrojándonos una serie de marcadores constitucionales de cómo debe entenderse la relación de esta institución con cada uno de los poderes del Estado. 
Debemos de partir sin duda de la controvertida, discutida naturaleza y ubicación constitucional del MF, dado que evidentemente la relación con el Parlamento se verá afectada por el locus constitucional que le atribuyamos a esta pieza clave de la arquitectura constitucional. En mi opinión se dibuja un modelo gubernativo con tintes judicialistas de Ministerio Público desde el mismo momento que se residencia en el gobierno la facultad de nombramiento del Fiscal General del Estado (art.124.4 CE), pieza clave en el funcionamiento del Ministerio Fiscal dado el carácter jerarquizado del mismo (art.124.2 CE).

Aunque la Carta Magna rechaza expresamente un modelo parlamentario de Ministerio Público, por cuanto no ha permitido expresamente la participación de este poder del Estado en el nombramiento de quien encabeza la institución, ello no significa que no haya de existir una adecuada relación entre Ministerio Fiscal y Parlamento. Es más, la Carta Magna permite sin necesidad de reforma o mutación constitucional incrementar el rol del Legislativo en todo lo concerniente al adecuado funcionamiento del MF.

Es obvio que la Constitución reconoce una autonomía al MF desde el mismo momento que exige que las altas misiones constitucionales las haga a "través de órganos propios". Esta autonomía no significa ni debe confundirse con una independencia a lo italiano. Pero tampoco debemos conceptuar al fiscal como un agente del Ejecutivo sumiso a la voz de su amo como ocurre en la vecina Francia. Por consiguiente, cuando el Fiscal General del Estado bien directamente a través de la Memoria Anual o bien a requerimiento de las Cámaras informa sobre el estado de la justicia y el papel de la institución fiscal está ofreciendo al primer poder del Estado un instrumento valioso de control parlamentario del gobierno de la nación. Pues es éste quien fundamentalmente se responsabiliza de la gestión y actuación de los fiscales y especialmente de quien los gobierna, el Fiscal General del Estado, nombrado y cesado por el propio gobierno. Realidad que se ve acusada por los propios principios de funcionamiento de la autoridad fiscal al actuar bajo los principios de unidad de actuación y dependencia jerárquica sin que ello entorpezca los otros dos grandes principios: el de legalidad y el de imparcialidad.

De manera indirecta las Cortes Generales reciben la colaboración del MF cuando éste informa las quejas planteadas ante el Defensor del Pueblo, Alto Comisionado de éstas (art. $54 \mathrm{CE}$ ), especialmente las referidas al funcionamiento de la Administración de Justicia.

En estos más de 25 años de vigencia de la Constitución de 1978 las propias Cortes Generales han evidenciado la necesidad de introducir modificaciones en el propio Ministerio Fiscal, lo que ha provocado diferentes reformas del EOMF, siendo la más significativa la efectuada por Ley 14/2003. Los diferentes grupos parlamentarios especialmente los que sucesivamente han ejercido la oposición han denunciado haciéndose eco de la opinión pública la conveniencia de al menos retocar el sistema de nombramiento del Fiscal General del Estado.

Ente las medidas sugeridas está la intervención del Parlamento en la designación y cese del Fiscal General del Estado. Tal y como hemos tenido ocasión de comentar tal participación no implica desapoderar a quien constitucionalmente cesa o nombra al Fiscal General del Estado que no es otro que el gobierno. 
Lamentablemente la tan esperada reforma al Estatuto Orgánico del Ministerio Fiscal no ha querido otorgar un mayor protagonismo al Parlamento, lo que en mi opinión ha sido un error. Es más, ha consagrado y mantenido el statu quo que venimos arrastrando desde los primeros gobiernos de la democracia.

Por todo lo anterior considero que si no se desea reformar constitucionalmente el MF, sí podríamos desde la flexibilidad que nos da el propio texto constitucional actual y a través del EOMF introducir una mayor participación de las Cámaras legislativas en todo lo concerniente al MF, especialmente en el nombramiento y cese del Fiscal General del Estado ya que el actual sistema de nombramiento es a todas luces manifiestamente insatisfactorio por el obvio riesgo de instrumentalización política que se pueda hacer del mismo.

\section{BIBLIOGRAFÍA}

Díez Bueso, L., Los Defensores del Pueblo (Ombudsmen) de las Comunidades autónomas, Secretaría General del Senado, Madrid, 1999.

Flores Prada, I., El Ministerio Fiscal en España, Tirant lo Blanch, Valencia, 1999.

García Mexía, P., "El poder en sempiterna crisis: apuntes de la actualidad sobre las Cortes Generales", en Revista del Poder Judicial, número 60, cuarto trimestre 2000, Madrid.

López Aguilar, J.F., La justicia y sus problemas en la Constitución, Justicia, jueces y fiscales en el Estado social y democrático de Derecho,Tecnos, Madrid, 1996.

López López, A., El Ministerio Fiscal Español. Principios orgánicos y funcionales, Colex, Madrid, 2001.

NArváez Rodríguez, A., "El Fiscal General del Estado y su relación con el gobierno. Reflexiones sobre su designación, mandato y cese", en Estudios Jurídicos, Ministerio Fiscal, Ministerio de Justicia, volumen V, Madrid, 2000.

Navas Castillo, F., "Las Comisiones de Investigación y el Poder Judicial", en Revista del Poder Judicial, número 60, cuarto trimestre 2000, Madrid.

Roig Bustos, L., "Por un Fiscal del Estado de designación parlamentaria”, en Revista Jueces para la Democracia, número 18, Madrid, 1993. 